\title{
Taylor Rule and Monetary Policy in Ghana
}

\author{
Mustapha Ibn Boamah \\ Correspondence: Mustapha Ibn Boamah, Department of Social Science, University of New Brunswick, Saint John, \\ E2L 4L5, Canada. Tel: 1-506-648-5760. E-mail: mboamah@unb.ca
}

Received: April 5, 2012

doi:10.5539/ijef.v4n7p15

\author{
Accepted: May 18, 2012 \\ Published: July 1, 2012 \\ URL: http://dx.doi.org/10.5539/ijef.v4n7p15
}

\begin{abstract}
Using time series estimations of simple forward and backward-looking Taylor type reaction functions to characterise monetary policy rules, this paper assesses to what extent these rules provide a description of interest rate response to inflation in Ghana, a developing African country widely regarded as having relatively strong state actors and good governance. Ghana's central bank officially adopted an inflation-targeting monetary policy in March 2002 following its operational independence. The paper finds that Taylor rule is not a good predictor of interest rate behaviour.
\end{abstract}

Keywords: Ghana, inflation targeting, monetary policy, Taylor rule

JEL classification: E52; E58; E61

\section{Introduction}

The economic goals of controlling inflation and limiting currency instability, to ensure long term economic growth, have been pursued principally through the tools of monetary policy. In the last quarter of a century, hitherto diffused objectives have been focused and price stability assigned primacy. Central banks increasingly have been assigned the agency role of achieving this central goal - in industrialised and developing countries alike. Moreover, the methods of monetary policy conduct have converged, with many developing countries increasingly adopting an explicit or implicit inflation targeting framework (Paez-Farrell, 2007), implemented with market oriented instruments such as short term interest rates (Maria-Dolores, 2005).

There is a considerable body of research work on monetary policy conduct in developed countries. Considering some contributions to the still limited literature on monetary policy conduct in the African context, Saxegaard (2006) examines the pattern of excess liquidity in Sub Saharan Africa (SSA) and its consequences for the effectiveness of monetary policy. Commercial banks may hold excess reserves due to asymmetric information problems, underdevelopment of bond markets in Africa and they may also do so due to lack of competition in the financial sector (O'Connell, 2005).

Saxegaard (2006) argues that understanding the consequences of excess liquidity requires quantifying the extent to which commercial bank holdings of excess liquidity exceed the levels required for precautionary purposes. His paper proposes a methodology for measuring this quantity and uses it to estimate a nonlinear structural vector autoregressive (VAR) model for the Economic and Monetary Community of Central Africa, Nigeria and Uganda (Note 1). Saxegaard's study suggests that excess liquidity weakens the monetary policy transmission mechanism and thus the ability of monetary authorities to influence demand conditions in the economy. Considering that Ghana has a similar financial environment as the countries studied, it would be worth knowing how effectively monetary managers influence demand conditions and inflation using the policy rate.

Following the completion of financial reforms and the economic recovery programme (ERP) in 1992, the Ghanaian economy moved towards a free market and a free market oriented monetary policy. Policy reforms included: a free floating exchange rate and trade liberalisation, growth-oriented and deficit-reducing fiscal policy characterised by a reduction in recourse to bank financing. Also, interest rates and credit had been decontrolled and structural and institutional reforms to facilitate the system of indirect monetary management put in place (Note 2). It is important to know the direction of monetary policy following these reforms.

This paper is therefore motivated by the fundamental role of monetary policy for macroeconomic stability, particularly price stability, and its subsequent implication for economic growth. The application of these ideas to Ghana, a small open developing economy, will contribute to the limited literature on monetary policy transmission in developing countries. 
The paper proceeds as follows. Section 2 sets up the model. Section 3 extends the basic model for estimation and comments on the data. Section 4 discusses the empirical results from the monetary reaction functions. Section 5 concludes.

\section{The Model}

\subsection{Taylor Rule and Its Applicability to Developing Countries}

The theoretical foundation for the analysis, the original Taylor rule (Taylor, 1993), is:

$$
i_{t}=\beta_{0}+\beta_{1}\left(\pi_{t}-0.02\right)+\beta_{2}\left(y_{t}-\tilde{y}_{t}\right)
$$

Where $i_{t}$ denotes the central bank's nominal interest rate (or instrument of policy); $\pi_{t}$, the inflation rate; $\left(y_{t}-\tilde{y}_{t}\right)$ is the output gap with $\mathrm{y}_{\mathrm{t}}$, being the log of real GDP; and $\tilde{y}_{\mathrm{t}}$, the log of potential output identified empirically with a linear trend. The number 0.02 is the 2 per cent inflation target, and $\beta_{0}$ is a benchmark recommendation when inflation and output are on target. This benchmark is also the sum of the 0.02 per cent inflation target and the assumed 0.02 per cent equilibrium real interest rate. The inflation gap and output gap coefficients are $\beta_{1}$ and $\beta_{2}$ respectively (Note 3 ).

The rule has been modified and used for many emerging economies (Aklan and Nargelecekenlar, 2008 and Vasicek, 2009). Taylor (2000) argues that market conditions in emerging market economies may require modifications to the rule recommended for the United States and economies with more developed financial markets.

\subsection{An Adaption of the Taylor Rule}

This paper proposes a rendition more suited to Ghana as a developing country following similar work by Hagan, 2004. This adapted rule involves amending two aspects of the rule: the inflation target and the equilibrium real interest rate. In May 2007, Ghana formally adopted an 'explicit' inflation targeting framework for its monetary policy, after five years of implicit inflation targeting (Note 4). The numerical target/forecast range for headline inflation is announced in the context of the annual budget, and the Bank of Ghana (BOG) communicates regularly its goals and decisions with the public and the markets. The central bank in May 2007 announced a medium term headline inflation target of 5 per cent with a band of $+/-1$ per cent (Note 5) that has been the bank's unannounced target for many years following the financial reforms. The bank also set some intermediate inflation targets/forecasts to achieve the medium term goal by the end of 2010 (Note 6) and keep headline inflation at 5 per cent target in the long run. Thus, the first modification of the Taylor rule is to replace 0.02 with 0.05 as Ghana's inflation target. Another difference is that in Ghana, the target is headline inflation unlike many inflation targeting economies where core inflation is the usual target.

The second modification involves using a more suitable equilibrium real interest rate, the rate of interest on a long term index linked bond. The interest rate on a five year Ghanaian bond (Golden Jubilee Saving Bonds) launched in March 2008 is 16.1 per cent. The annual inflation rate is about 10 percent (BOG, 2009). Thus, the appropriate equilibrium real rate is taken as 6 percent (Note 7). Ghana's real GDP growth rate has averaged between 5.0 and 6.0 per cent in the last five years (BOG, 2009).

The figure 0.06 , thus, replaces the 0.02 equilibrium real interest rate of the Taylor rule. With these two modifications and using Taylor's proposed values of $\beta_{1}=1.5$ and $\beta_{2}=0.5$, the rule amended for Ghana is:

$$
i_{t}=0.11+1.5\left(\pi_{t}-0.05\right)+0.5\left(y_{t}-\tilde{y}_{t}\right)
$$

The benchmark recommendation, being the sum of the estimated equilibrium real interest rate and the inflation target, is now 11 per cent.

Teles and Zaidan (2010) argue that policy reaction functions of the Taylor specification assume stationarity of the data series. For developing countries and countries undergoing financial reforms, stationarity of data cannot be taken for granted.

To solve the stationarity problem, this paper adopts the conditional error-correction model (ECM) developed by Pesaran, Shin and Smith (2001), which is robust to the stationarity properties of the data. This model works well whether the underlying regressors are purely $\mathrm{I}(1), \mathrm{I}(0)$ or mutually cointegrated.

The conditional ECM to estimate is given by (Note 8)

$$
\begin{gathered}
\Delta i_{t}=\boldsymbol{c}_{\mathbf{0}}+\boldsymbol{b}_{\mathbf{1}} i_{t-1}+\boldsymbol{b}_{\mathbf{2}} \text { inflation.gap }_{(t-1)}+\boldsymbol{b}_{\mathbf{3}} \text { output.gap }_{(\boldsymbol{t}-\mathbf{1})}+\sum_{j=\mathbf{1}}^{\boldsymbol{k}} \sum_{\boldsymbol{m}=\mathbf{0}}^{\boldsymbol{p}} \boldsymbol{\psi}_{j \mathrm{~m}} \Delta X_{j(t-m)}+\sum_{\boldsymbol{m}=\mathbf{1}}^{\boldsymbol{p}} \boldsymbol{\delta}_{\boldsymbol{m}} \Delta i_{t-m} \\
+\mu_{t}
\end{gathered}
$$


Where $\mathbf{c}_{\mathbf{0}} \neq 0 ; i_{t}$ is the policy interest rate, $\Delta \mathrm{X}_{\mathrm{j}(\mathrm{t}-\mathrm{m})}$ the inflation gap and output gap vector in difference, and $\mu_{\mathrm{t}}$ serially uncorrelated errors. The model allows for both short run and long run dynamics and provides a link between the variables and the steady state equilibrium.

The long run coefficients are derived by assuming that all variables are constant in equilibrium, so that Equation (3) reduces to:

$$
\boldsymbol{c}_{\mathbf{0}}+\boldsymbol{b}_{\mathbf{1}} \text { policy.rate }+\boldsymbol{b}_{\mathbf{2}} \text { inflation.gap }+\boldsymbol{b}_{\mathbf{3}} \text { output.gap }+\mu=0
$$

The constant and level explanatory variables then have their long run parameters given by:

$$
w_{0}=c_{0} / \hat{b}_{1}, w_{1}=\hat{b}_{2} / \hat{b}_{1} \text { and } w_{2}=\hat{b}_{3} / \hat{-b}_{1}
$$

where $b_{1}$ is the coefficient on the lagged level policy rate variable, $c_{0}$ is the constant term, $b_{2}$ and $b_{3}$ are the coefficients associated with the lagged level explanatory variables (inflation gap and output gap) in the short run model. Therefore equation (4) can be re-arranged as (Note 9):

$$
\text { policy.rate }=\mathbf{w}_{\mathbf{0}}+\mathbf{w}_{\mathbf{1}} \text { inflation. gap }+\mathbf{w}_{\mathbf{2}} \text { output. gap }+\mu
$$

The inflation gap and output gap coefficients are compared, respectively, with the original Taylor rule values of 1.5 and 0.5 Taylor (1993), to assess the inflation stabilising policy rule of the central bank.

\section{Data and Model Estimation}

The strict inflation targeting rules are estimated using monthly data from 1993:01 to 2011:12 on the policy rate and inflation, and the output gap is added to estimate the Taylor rule (Note 10). The instrument of monetary policy used is the policy rate. The headline inflation is measured by its seasonally-adjusted annual percentage change. Data is drawn from the IMF international financial statistics database and the monetary time series database of the Bank of Ghana (Note 11).

In the empirical analysis, the pace of economic activity is measured using the Hodrick and Prescott filter as the deviation from growth or trend of the log of real seasonally adjusted private sector credit, following Khan (2003) and Hagan (2004) (Note 12). The Hodrick and Prescott filter assumes that the growth component which is a function of time is extracted from the log of real seasonally adjusted private sector credit through the minimisation of the transitory component. Hodrick and Prescott (1997) propose a 'lambda' value of 100 multiplied by the square of the frequency of output for their filter (Note 13).

The paper seeks to investigate two inflation stabilising policy rules scenarios with the data: the first being one of strict inflation targeting; and the other, that inflation gap and the output gap, as proposed in the Taylor rule, are the important variables that predict interest rate behaviour.

\section{Empirical Results}

This section characterises Ghana's monetary policy by investigating the consistency of two hypotheses for inflation control. It thus investigates first, inflation targeting in its basic form; and second, using the inflation and output gaps for monetary policy conduct. 


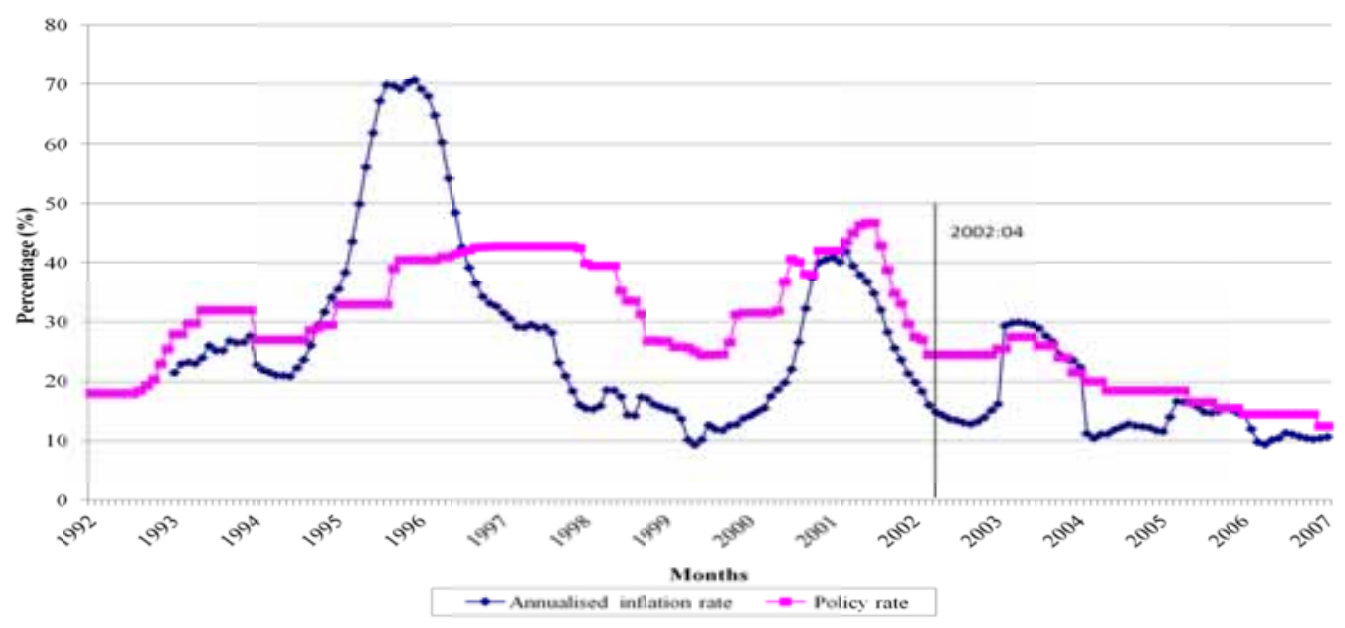

Figure 1. A plot of the Policy rate and Inflation

The figure above shows inflation has been much more volatile than the policy rate. It also shows a sharp fall, then continuous decline thereafter, in the policy rate in 2002, which may be a sign of a structural break in the dataset. A dummy variable (taking the value 0 to 2002:03 and 1 from 2002:04) is included to check for structural breaks. Increased government spending and a rise in dollarization leading to the general election in December, 1996 contributed to high inflation in that year. The sharp rise in inflation in February 2003 came from both food and non food sources as a result of high food prices and a weakened exchange rate. The estimation results are presented in Table 1 and 2.

\subsection{Short Run Analysis}

Investigating the strict inflation targeting scenario with the data involves the use of lags of monthly changes of inflation gap and the policy rate in both forward and backward looking inflation stabilising rules. The dummy variable is significant in the backward looking model (see appendix Table 2) confirming a structural break in the data set. The data is therefore split in two, to investigate strict inflation targeting. Results of the dataset from 1993:01 to 2002:03 are shown as equation 3a (1) and that of the dataset from 2002:04 to 2011:12 as equation 3a (2). The final form of the model which includes the output gap with dataset from 2002:04 to 2011:12 is shown as equation $3 \mathrm{~b}$. The forward and backward looking inflation stabilisation rules consistent with the Taylor rule begin with twelve lags of monthly changes in the policy rate (Note 14), inflation gap and the output gap are reported in appendix Tables 1 and 2 respectively.

Comparing $F$-statistic and $t$-statistic of both the backward-looking models and the forward-looking models with their 5 per cent critical value bounds confirms the existence of a relationship in levels of forward-looking equations 3a (2) and $3 b$ (Note 15). The statistics also confirms that a relationship exist in backward-looking equation 3a (1) and confirms the presence of a structural break in the backward-looking model (Note 16)

The inflation gap in levels is correctly signed and significant in equation 3a (2) suggesting that the period from 2002:04 to 2011:12 appears to show some form of inflation targeting from the short run analysis. The policy regime that started after the central bank's operational independence in March 2002 allows for the monetary policy committee of the central to meet and reassess the policy rate every other month. A negative differential intercept (dummy) coefficient confirms a monetary policy shift from high policy rates between 1993 and March 2002 to low policy rates after March 2002 as headline inflation falls.

\subsection{Long Run Analysis}

From equation 5, the long run coefficients for equation $3 \mathrm{a}$ (1) are given by:

$$
\text { policy.rate }=0.262+0.354 \text { inflation.gap }
$$


The low coefficient on the inflation variable suggests that monetary policy did not follow strict inflation targeting in Ghana in the period from 1993:01 to 2002:02.

The long run coefficients for equation $3 \mathrm{a}(2)$ is given by:

$$
\text { policy.rate }=0.088+0.725 \text { inflation.gap }
$$

The higher inflation coefficient may result from the central bank establishing an implicit inflation targeting framework in 2002, though the value is not identical to the reference value of 1.5 proposed by the original Taylor rule. It thus represents a shift in the policy framework of the central bank's inflation stabilisation policy in the period 2002:04 to 2011:12. This period shows less volatility, declining inflation and the policy rate.

Repeating this exercise for Equation $3 \mathrm{~b}$ yields:

$$
\text { policy.rate }=0.092+0.737 \text { inflation }+0.066 \text { output.gap (Note 17) }
$$

The insignificant policy rate response to the output gap and the small policy rate response to inflation - less than the reference value of 1.5 proposed by the original Taylor rule and even lower then unity (Note 18) - suggests an absence of central bank commitment to price stability based on the Taylor rule over 2002:04 to 2011:12.

The use of detrended private sector credit as a proxy for output gap only makes sense if there is a strong same directional relationship between the two variables. Also since detrended private sector credit is a cyclical measure which corresponds to economic fluctuations, mainly relating to the cyclical components in the economy, the insignificance of the output gap proxy may be due to shocks dominating private sector credit availability following financial and economic reforms.

\section{Conclusions}

Taylor rule models have been a benchmark for describing a good monetary policy. However, many authors have proposed various renditions of the standard Taylor rule specification to account for differences in structure and stages of economic and financial reforms.

Results from this Taylor rule show a weak relationship between the policy rate and inflation, suggesting that the central bank is executing an accommodative monetary policy, though excess liquidity may be a problem too (Note 19). The insignificance of the output gap may be due shocks dominating private sector credit volatility since this paper uses de-trended private sector credit as a proxy for output gap. Detrended private sector credit is a cyclical measure which this paper assumes corresponds to economic fluctuations, mainly related to the cyclical components in the economy.

However, following the financial sector reforms which started in 1992 and in particular after March 2002 the central bank has made progress in its inflation stabilising policy. The strict inflation targeting is intended to provide benefits in terms of a credible commitment to controlling inflation, along with a more consistent and predictable monetary policy direction. The relatively stronger link between the policy rate and inflation after March 2002 represents a shift in the policy framework in the central bank's inflation stabilisation policy.

The answer may well be with a shift from short term inflation forecasts and a target that is either not announced or not credible as a primary monetary objective to explicit inflation targeting with a clearer commitment to controlling inflation. This policy framework would include announced inflation targets in the medium term and would allow policy rate increases to levels that are necessary to keep inflation within the target boosting policy credibility and, ultimately, ensuring low inflation.

Finally, a mainstream approach in literature is to estimate the constant term as the sum of equilibrium real interest rate and the inflation target. However, because of the difficulties in deriving accurate measures of these variables from the data and the fact that the models do not adequately describe the conduct of monetary policy in Ghana, this paper does not give any structural interpretation to the constant term.

\section{References}

Aklan, N. A., \& Nargelecekenler, M. (2008). Taylor Rule in Practice: Evidence from Turkey. Journal of Business and Economics, 14, 156-166.

Alichi, A., Clinton, K., Dagher, J., Kamenik, O., Laxton, D., \& Mills, M. (2009). A Model for Full - Fledged Inflation Targeting and Application to Ghana. IMF Working Paper, 10/25.

Bank of Ghana. (2009). Quarterly Economic Bulletin: January - March. Accra: Bank of Ghana.

Clarida, R., Gali, J., \& Gertler, M. (2000). Monetary Policy Rules and Macroeconomic Stability: Evidence and Some Theory. Quarterly Journal of Economics, 115, 147-180. http://dx.doi.org/10.1162/003355300554692 
Hagan, A. (2004). The Conduct and Effectiveness of Monetary Policy in Four African Countries. Mimeo, University of Nottingham.

Hodrick, R. J., \& Prescott, E. C. (1997). Post-war US Business Cycles: an Empirical Investigation. Journal of Money, Credit and Banking, 29, 1-16. http://dx.doi.org/10.2307/2953682

Khan, M. (2003). Current Issues in the Design and Conduct of Monetary Policy. Paper presented to the RBI/GIDR Fifth Annual Conference on Money and Finance in the Indian Economy, 30 January to 1 February.

Maria-Dolores, R. (2005). Monetary Policy Rules in Accession Countries in the EU: Is the Taylor Rule a Pattern? Economic Bulletin, 5, 1-16.

O'Connell, S. (2005). Notes on Excess Liquidity. Mimeo, International Monetary Fund.

Paez-Farrell, J. (2007). Understanding Monetary Policy in Central European Countries Using Taylor-type Rules: the case of the Visegrad Four. Economic Bulletin, 5, 1-11.

Pesaran, H. M., Shin, Y., \& Smith, R. J. (2001). Bounds Testing Approaches to the Analysis of Level Relationship. Journal of Applied Econometrics, 16, 289-326. http://dx.doi.org/10.1002/jae.616

Saxegaard, M. (2006). Excess Liquidity and Effectiveness of Monetary Policy: Evidence from sub- Saharan Africa. IMF Working Paper 06/115.

Taylor, J. B. (1993). Discretion versus Policy Rules in Practice. Carnegie-Rochester Conference Series on Public Policy, 39, 195-214. http://dx.doi.org/10.1016/0167-2231(93)90009-L

Taylor, J.B. (2000). Using Monetary Policy Rules in Emerging Market Economies. Revised Paper presented at the $75^{\text {th }}$ Anniversary Conference, Stabilisation and Monetary Policy: The International Experience, Bank of Mexico, 14 -15 November.

Teles, V. K., \& Zaidan, M. (2010). Taylor Principle and Inflation Stability in Emerging Market Countries. Journal of Development Economics, 91, 180-83. http://dx.doi.org/10.1016/j.jdeveco.2009.07.007

Vasicek, B. (2009). Monetary Policy Rules and Inflation Process in Open Emerging Economies: Evidence for 12 new EU members. Les Cahiers de Recherche de l'ESCE, 11, 451-476.

\section{Notes}

Note 1. The Central African grouping, known as CEMAC (Communauté Économique et Monétaire de l'Afrique Centrale) was established by Cameroon, Central African Republic, Chad, Congo, Equatorial Guinea and Gabon to promote economic integration among countries that share a common currency, the CFA franc.

Note 2. Structural and institutional reforms to encourage competition and the development of the bond market among others.

Note 3. Taylor (1993) proposes $\beta_{1}=1.5$ and $\beta_{2}=0.5$ to accurately predict US Federal Reserve rates over the period 1987-1992.

Note 4. Where Ghana established an inflation target but did not announce it as its primary monetary policy objective.

Note 5. See Alichi et al (2009).

Note 6. A missed target, headline inflation was 8.58 per cent in December 2010 and 10.75 yearly average.

Note 7. This paper uses a simple method to determine the equilibrium real interest rate as there is no available time series data on it.

Note 8. It's a backward-looking model.

Note 9. See Pesaran, Shin and Smith (2001).

Note 10. Institutional arrangements were put in place by 1993 to facilitate indirect monetary management following the economic recovery programme which began in 1983 and was completed in 1992.

Note 11. Both the IMF and the Bank of Ghana use the same variable names.

Note 12. Gross domestic product data is not available on a monthly basis.

Note 13. For monthly data 'lambda' is 14400.

Note 14. The number of lags is determined by the Akaike Information Criteria.

Note 15. See Perasan, Shin and Smith (2001) for critical values. 
Note 16. See tables in appendix.

Note 17. Not significant at 10 per cent.

Note 18. See Clarida et al., (2000).

Note 19. See Saxegaard (2006).

Appendix

Table 1. Short Run Forward-Looking Analysis Results (created using EViews)

\begin{tabular}{lllll}
\hline Regressor & $\begin{array}{l}\text { Structural } \\
\text { Break Test }\end{array}$ & Equation 3a(1) & Equation 3a(2) & Equation 3b \\
& 0.008 & 0.005 & 0.007 & 0.007 \\
C & $(0.006)$ & $(0.008)$ & $(0.003)$ & $(0.003)$ \\
policy.rate(-1) & $-0.043^{* *}$ & -0.030 & $-0.080^{* *}$ & $-0.076^{* *}$ \\
inflation.gap & $(0.017)$ & $(0.025)$ & $(0.025)$ & $(0.025)$ \\
dummy & $0.028^{* *}$ & $0.023^{* *}$ & $0.058^{* *}$ & $0.056^{* *}$ \\
output.gap & $(0.008)$ & $(0.010)$ & $(0.019)$ & $(0.020)$ \\
& $0.197^{* *}$ & $0.316^{* *}$ & $-0.201^{* *}$ & $-0.201^{* *}$ \\
& $(0.066)$ & $(0.094)$ & $(0.090)$ & $(0.091)$ \\
& -0.004 & & & 0.005 \\
& $(0.003)$ & & & $(0.012)$ \\
& & & & \\
\hline R-squared & 0.128 & 0.186 & 0.113 & 0.114 \\
F-statistic & 8.090 & 8.061 & 4.753 & 3.541 \\
SE of regression & 0.012 & 0.015 & 0.008 & 0.008 \\
policy.rate(-1) $t$-statistic & -2.493 & -1.200 & -3.242 & -3.081 \\
\hline
\end{tabular}

Table 2. Short Run Backward-looking Analysis Results (created using EViews)

\begin{tabular}{lllll}
\hline Regressor & Structural & Equation & $\begin{array}{l}\text { Equation } \\
3 \mathrm{a}(2)\end{array}$ & $\begin{array}{l}\text { Equation } \\
3 \mathrm{~b}\end{array}$ \\
\hline $\mathrm{C}$ & Break Test & $3 \mathrm{a}(1)$ & 0.003 & 0.003 \\
policy.rate(-1) & 0.012 & 0.017 & $(0.003)$ & $(0.003)$ \\
inflation.gap & $(0.006)$ & $(0.008)$ & -0.027 & -0.026 \\
dpolicy.rate & $-0.050^{* *}$ & $-0.065^{* *}$ & $(0.025)$ & $(0.025)$ \\
dinflation.gap & $(0.018)$ & $(0.025)$ & $0.002^{*}$ & 0.001 \\
dummy & $0.0216^{* *}$ & $0.023^{* *}$ & $(0.020)$ & $(0.021)$ \\
output.gap & $(0.008)$ & $(0.010)$ & $-0.202^{* *}$ & $-0.202^{* *}$ \\
& $0.239^{* *}$ & $0.384^{* *}$ & $(0.087)$ & $(0.088)$ \\
& $(0.065)$ & $(0.089)$ & $-0.145^{* *}$ & $0.146^{* *}$ \\
& $0.069^{*}$ & & $(0.043)$ & $(0.043)$ \\
& $(0.040)$ & & & 0.001 \\
& $-0.006^{*}$ & & & $(0.012)$ \\
\hline R-squared & $(0.003)$ & & 0.132 & 0.132 \\
F-statistic & 0.141 & 0.189 & 4.263 & 3.382 \\
SE of regression & 7.166 & 9.387 & 0.008 & 0.008 \\
policy.rate(-1) $t$-statistic & 0.012 & 0.015 & -1.071 & -1.029 \\
\hline ** Signific $95 \%$ con & -2.833 & -2.593 & & \\
\hline
\end{tabular}

Notes: ** Significant at $95 \%$ confidence level; * Significant at $90 \%$ confidence level

The dependent variable is change in the policy interest rate, dpolicy. rate. Standard errors are in parentheses. Variables preceded by ' $d$ ' are the one month differences of the respective variable in levels. 